\title{
BMJ Open Cause-specific sickness absence trends by occupational class and industrial sector in the context of recent labour market changes: a Finnish panel data study
}

\author{
Taina Leinonen, Eira Viikari-Juntura, Kirsti Husgafvel-Pursiainen, \\ Svetlana Solovieva
}

To cite: Leinonen T, ViikariJuntura E, HusgafvelPursiainen $\mathrm{K}$, et al. Causespecific sickness absence trends by occupational class and industrial sector in the context of recent labour market changes: a Finnish panel data study. BMJ Open 2018;8:e019822. doi:10.1136/ bmjopen-2017-019822

- Prepublication history and additional material for this paper are available online. To view these files, please visit the journal online (http://dx.doi org/10.1136/bmjopen-2017019822).

Received 27 September 2017 Revised 17 February 2018 Accepted 5 March 2018
Check for updates

Finnish Institute of Occupational Health, Helsinki, Finland

Correspondence to

Dr Taina Leinonen;

taina.leinonen@ttl.fi

\section{ABSTRACT}

Objectives We aimed to provide previously unestablished information on population-based differences in causespecific sickness absence trends between occupational classes and further between four large industrial sectors within the different occupational classes while controlling for other socioeconomic factors and employment patterns. We focused on the period 2005-2013, during which the labour market underwent large economic and structural changes in many countries.

Design Register-based panel data study.

Setting Large representative datasets on Finnish wage earners aged $25-59$ years.

Outcome measure Annual risk of sickness absence ( $>10$ working days) based on repeated logistic regression. Results Between 2005 and 2013, the proportion of employees with sickness absence decreased. Occupational class differences in sickness absence trends varied by disease group. Overall, the decrease in absences was smallest among lower non-manual employees. Sickness absence levels were highest in the health and social work sector and in the manufacturing sector within the non-manual and manual classes, respectively. Absences due to musculoskeletal diseases decreased temporarily during the peak of the economic recession in 2009, particularly in the manufacturing sector within the manual class. The decrease in absences due to musculoskeletal diseases was smallest in the trade sector within the lower occupational classes. Overall, education, income and employment patterns partly explained the differences in the absence levels, but not in the trends.

Conclusions We found a complex interplay between the associations of occupational class and industrial sector with sickness absence trends. During the economic recession, absences due to musculoskeletal diseases decreased temporarily in a segment of wage earners who were known to have been hit hard by the recession. However, the trend differences were not explained by the measured structural changes in the characteristics of the study population. Both occupational class and industrial sector should be taken into account when tackling problems of work disability.

\section{Strengths and limitations of this study}

- The large register-based datasets were representative of Finnish wage earners and did not have the problem of missing information due to non-response.

- The data had sufficient statistical power for examining cause-specific sickness absence trends by large industrial sectors within different occupational classes.

- The rich data included information on various covariates, including education, employment sector, income, time spent in employment and the number of employment episodes.

- The data lacked information on some potentially important covariates such as health status, lifestyle factors, work exposures and labour market conditions.

- The sickness absence outcome was based on national data on compensated spells that begin after a period of 10 working days, thereby excluding shorter spells.

\section{INTRODUCTION}

The association of low occupational class with a higher likelihood of sickness absence has been established in many European countries. $^{1-11}$ The occupational class differences have been particularly large in absences due to musculoskeletal diseases, and smaller but still notable in most other disease groups. In mental disorders, the absence levels have been similar or even higher among lower non-manual employees than among manual workers. $^{2} 10$

In addition to occupational class, industrial sector is closely associated with working conditions and the broader work environment, which affect the ability of an individual to perform in his or her own job. A previous study from Denmark indicated that the risk of long-term sickness absence was higher than 
average in the healthcare and social services sector and lower than average in the private administration sector, but otherwise the differences between the sectors were small. ${ }^{12}$ Accordingly, a Norwegian study indicated that the risk of long-term sickness absence was higher among women employed in health and social occupations than among the general female-employed population. ${ }^{13}$ There may also be an important interplay between occupational class and industrial sector; even within a particular occupational class, the types of jobs may vary considerably between different sectors. Previous population-based findings from Denmark ${ }^{12}$ and Sweden ${ }^{14}$ have shown large differences in long-term sickness absence between particular occupational groups. Variation in sickness absence between industrial sectors within different occupational classes nevertheless remains unclear.

From the start of the millennium, Finland and other European countries have experienced two key labour market changes that may have had varying consequences for the health, work ability and illness behaviour of individuals in different occupational classes and industrial sectors. First, particular sectors including manufacturing and construction were hit hard by the economic recession of the late 2000s, whereas other sectors such health and social services were less affected. ${ }^{15}$ In Finland, the economic recession peaked in 2009. This was the only year in which the change in the gross domestic product (GDP) was negative $(-6.5 \%)$. A specific feature for Finland was that there was another decline in the GDP growth after 2011. The manufacturing sector was affected the most: the number of wage earners employed in this sector decreased by $9.4 \%$ between 2008 and 2009, while the corresponding decrease in the total wage-earner population was $3.8 \% .{ }^{16}$ Second, the labour market has undergone long-term structural changes through which employment in non-manual occupations as well as in the knowledge work and service sectors has increased. ${ }^{16} 17$ These economic and structural changes are likely to have been associated with changes in the types of jobs as well as in the work, employment and social conditions of individuals within particular occupational classes and industrial sectors.

Recent economic and structural changes in the labour market may have led to changes in the associations of occupational class and industrial sector with sickness absence. Previous studies from Finland indicated that during recent decades, the overall level as well as occupational class differences in sickness absence have mainly decreased. ${ }^{9-11}$ However, the contribution of the recession of the late 2000s to changes in the occupational class differences in sickness absence remains unclear. Moreover, information on trends in sickness absence by industrial sector are altogether lacking. Further, little is known of whether occupational class and industrial sector differences in sickness absence trends can be attributed to longer-term structural changes in the labour market, such as those related to educational attainment, income, private versus public sector employment or other employment patterns. Information on sickness absence trends and their explanations would help identify vulnerable groups in order to prevent work disability and extend working careers.

We used large register-based datasets to examine cause-specific sickness absence trends in 2005-2013 by occupational class and further by industrial sector among the general population of Finnish wage earners while accounting for other socioeconomic factors and employment patterns. We thereby aimed to explore whether occupational class and industrial sector differences in cause-specific sickness absence trends were influenced by changes in the characteristics of the wage-earner population over a period of major economic fluctuations. The more particular research questions are listed below.

1. Do the trends in sickness absence due to all causes, musculoskeletal diseases, mental disorders, neoplasms, circulatory diseases, respiratory diseases or digestive diseases differ between occupational classes?

2. Do the trends in sickness absence due to the two largest disease groups, that is, musculoskeletal diseases and mental disorders, vary between four large industrial sectors within different occupational classes?

3. Are the occupational class and industrial sector differences in cause-specific sickness absence trends influenced by changes over the study period in education, employment sector, income, time spent in employment and the number of employment episodes?

\section{MATERIAL AND METHODS}

\section{Study population}

We used large register-based datasets with $70 \%$ nationally representative random samples of the Finnish working-aged population from three cross-sections on the last days of the years 2004, 2007 and 2010. Each of the cohorts was followed up for three calendar years to cover a 9-year study period between 2005 and 2013. The data included information on compensated sickness absences and national pensions obtained from the Social Insurance Institution of Finland, on sociodemographic factors obtained from the Finnish Longitudinal Employer-Employee Data of Statistics Finland, and on employment and earnings-related pensions from the Finnish Centre for Pensions, as also described in our previous study on gender differences in sickness absence. ${ }^{18}$

Criteria for being included in the study population were applied separately to each study year. An individual could thus be excluded in 1 year and included in others. We restricted the study population to those aged 25-59 on the last day of the year preceding the study year. We included individuals who were employed wage earners according to their main economic activity and socioeconomic status and did not receive full pensions (full disability pensions, unemployment pensions, special pensions for farmers or old-age pensions) before the study year. We also required that the study person had an ongoing employment period (in the private sector, in 
the public sector or in both, but not in self-employment) and did not have an ongoing compensated sickness absence spell at the beginning of the study year. The excluded were subsequently either self-employed $(8.7 \%$ of the original study population), unemployed (8.0\%), retired $(14.1 \%)$, otherwise non-employed $(9.9 \%)$ or on sick leave $(0.8 \%)$. We allowed for non-employment and self-employment later during the study year, adjusting for these factors in the analyses. We nevertheless excluded those who started receiving full pensions $(0.2 \%)$, emigrated $(0.1 \%)$ or died $(0.05 \%)$ during the study year. Finally, we excluded those who did not live in Finland 2years before the end of the year preceding the study year $(0.2 \%)$. We did this because we used the population samples from the end of years 2004, 2007 and 2010 to form the study population in years 2005-2007, 2008-2010 and 2011-2013, respectively; since the study population in years 2007, 2010 and 2013 by design lived in Finland 2 years before, we applied the same inclusion criteria for all of the years.

After all exclusions, $74.0 \%$ of the remaining individuals were included in the study population in each of the three consecutive years (calculated among those who fit the age range $25-59$ in all 3 years). The final study population consisted of around 1.1 million individuals per study year (online supplementary table 1 ).

\section{Sickness absence outcome}

For permanent Finnish residents, sickness absence is compensated by the Social Insurance Institution of Finland after a period of 10 working days that are typically paid by the employer. ${ }^{19}$ Only sickness absence spells compensated by the Social Insurance Institution are registered at the national level and included in our data. The outcome of this study was therefore based on sickness absence that by definition lasted around two calendar weeks or more. We used repeated dichotomous measures of whether a study person had a new onset of compensated sickness absence in a particular calendar year. The outcome included both full and part-time sickness absence, but in Finland the first onset of work disability typically starts with full sickness absence.

Cause-specific sickness absence was classified according to the 10th revision of the International Classification of Diseases. We examined six large groups separately, including (1) musculoskeletal diseases (diseases of the musculoskeletal system and connective tissue, M00-M99), (2) mental disorders (mental and behavioural disorders, F00-F99), (3) neoplasms (C00D48), (4) circulatory diseases (I00-I99), (5) respiratory diseases (J00-J99) and (6) digestive diseases (K00-K93). We did not examine the large disease group consisting of injuries, because absences due to some injuries, including occupational, traffic and military accidents, are covered by other insurers than the Social Insurance Institution of Finland and therefore not included in our data.

\section{Occupational class and industrial sector}

Occupational class and industrial sector were based on information measured in the year preceding each study year and categorised according to classifications by Statistics Finland.$^{20}$ Occupational class consisted of categories (1) upper non-manual, (2) lower non-manual and (3) manual.

Industrial sector included the following categories: (1) manufacturing (manufacturing, mining and quarrying), (2) trade (wholesale and retail trade; repair of motor vehicles and motorcycles), (3) knowledge work (information and communication; financial and insurance activities; real estate activities; professional, scientific and technical activities), (4) human health and social work activities and (5) other (agriculture, forestry and fishing; electricity, gas, steam and air conditioning supply; water supply; sewerage, waste management and remediation activities; construction; transportation and storage; accommodation and food service activities; administrative and support service activities; public administration and defence; compulsory social security; education; arts, entertainment and recreation; other service activities; activities of households as employers; undifferentiated goods-producing and services-producing activities of households for own use; activities of extraterritorial organisations and bodies; industry unknown). This classification was from year 2008. Until 2007, the classification was based on an older version from year 2002, but virtually equivalent main categories listed above could be constructed using a reclassification code provided by Statistics Finland.

When examining industrial sectors within the three occupational classes, we only show results for the four large industrial sectors 1-4. The category 'other' consisted of heterogeneous smaller sectors which could not be examined separately due to small number of events.

\section{Covariates}

We examined sociodemographic factors and employment patterns as covariates. Age was divided into 5-year groups. Education and income were based on information measured in the year preceding each study year. Education consisted of categories (1) higher tertiary (Master's or equivalent level, or higher), (2) lower tertiary (Bachelor's or equivalent level), (3) secondary and (4) primary. Tertiary education was divided into two levels, because the proportion of those with higher tertiary education in particular increased during the study period (online supplementary table 1). Income consisted of both wage and capital income of the individual. It was inflation corrected and then divided into quintiles across the study years.

Employment patterns were measured during each study year. Employment sector was classified as (1) private, (2) public, (3) private and public and (4) transition to self-employment. Time spent in employment was divided into (1) full year, (2) 200-364 days and (3) 1-199 days. The cut-point of 200 days was arbitrarily chosen to define 
those who were employed most of the year. The number of employment episodes was divided into (1) one, (2) two and (3) three or more.

\section{Statistical methods}

We used generalised estimation equations (GEE) based on repeated logistic regression to estimate the annual risk of having a new onset of compensated all-cause and cause-specific sickness absence in 2005-2013. The GEE models account for the within-individual correlation between repeated measurements in the three different samples followed up during periods 2005-2007, 20082010 or 2011-2013.

Using margins derived from the logistic GEE models, we plotted trajectories of estimated proportions (\%o) of employees with sickness absence including interactions of occupational class and industrial sectors within the occupational classes with categorical year. Estimated proportions demonstrate the magnitude and direction of changes in the level of sickness absence among different groups, which would not be revealed solely on the basis of information on changes in the differences between the groups. Analyses of occupational class differences were performed in each of the six disease groups. Analyses of differences between industrial sectors within the different occupational classes were performed in the two largest disease groups, that is, musculoskeletal diseases and mental disorders. We adjusted for the annually measured covariates holding them at their mean level when plotting the trajectories.

Derived from the same GEE models, we also calculated relative differences between industrial sectors within the different occupational classes. We used those employed in the knowledge work sector as the reference group, for which the OR of sickness absence was held at 1.00 in each year.

We pooled men and women, adjusting for gender in the analyses. Even though the overall level of sickness absence was much higher among the female than the male study population, changes over time were relatively similar among the genders especially after accounting for their differential occupational and sectoral distributions. ${ }^{18}$

\section{RESULTS}

\section{Characteristics of the study population}

Over the study period between 2005 and 2013, the proportion of manual workers decreased especially in the manufacturing sector, but also in the health and social work sector (table 1). The proportion of non-manual employees increased. Among upper non-manual employees, the increase was largest in the knowledge work sector. Among lower non-manual employees, the proportion increased in the health and social work sector and decreased in the manufacturing sector. Annual distributions of the study population by all background

\begin{tabular}{|c|c|c|c|c|c|c|c|c|c|}
\hline Occupational class & Year & & & & & & & & \\
\hline Upper non-manual & 24.3 & 25.2 & 25.4 & 25.6 & 26.4 & 26.9 & 25.8 & 26.0 & 26.1 \\
\hline Manufacturing & 3.1 & 3.3 & 3.5 & 3.5 & 3.7 & 3.6 & 3.5 & 3.5 & 3.3 \\
\hline Health and social work & 2.9 & 2.9 & 2.9 & 2.9 & 3.0 & 3.1 & 3.1 & 3.2 & 3.3 \\
\hline Other & 11.6 & 11.9 & 11.8 & 11.8 & 12.0 & 12.4 & 11.6 & 11.7 & 11.9 \\
\hline Lower non-manual & 40.8 & 40.2 & 40.2 & 40.4 & 40.7 & 41.3 & 42.7 & 42.7 & 43.1 \\
\hline Manufacturing & 4.4 & 4.0 & 4.0 & 4.0 & 3.9 & 3.7 & 3.5 & 3.4 & 3.4 \\
\hline Other & 11.3 & 11.2 & 11.1 & 10.9 & 10.9 & 11.1 & 12.4 & 12.2 & 12.1 \\
\hline Manual & 34.9 & 34.6 & 34.3 & 34.0 & 33.0 & 31.9 & 31.5 & 31.4 & 30.9 \\
\hline Manufacturing & 12.5 & 12.3 & 12.1 & 11.9 & 11.3 & 10.3 & 10.3 & 10.2 & 9.8 \\
\hline Trade & 2.3 & 2.2 & 2.2 & 2.2 & 2.2 & 2.1 & 2.2 & 2.1 & 2.2 \\
\hline Knowledge work & 1.1 & 1.1 & 1.0 & 1.0 & 1.0 & 1.0 & 0.9 & 0.9 & 0.8 \\
\hline Health and social work & 2.3 & 2.2 & 2.1 & 2.0 & 1.9 & 1.8 & 1.8 & 1.6 & 1.6 \\
\hline Other & 16.7 & 16.8 & 16.9 & 16.9 & 16.6 & 16.7 & 16.5 & 16.6 & 16.5 \\
\hline Total & 100 & 100 & 100 & 100 & 100 & 100 & 100 & 100 & 100 \\
\hline
\end{tabular}


Table 2 Age-adjusted and gender-adjusted estimated annual proportion of employees with a new onset of all-cause sickness absence (\%o and $95 \% \mathrm{Cl}$ ) and the annual change (\%) over particular years by occupational class

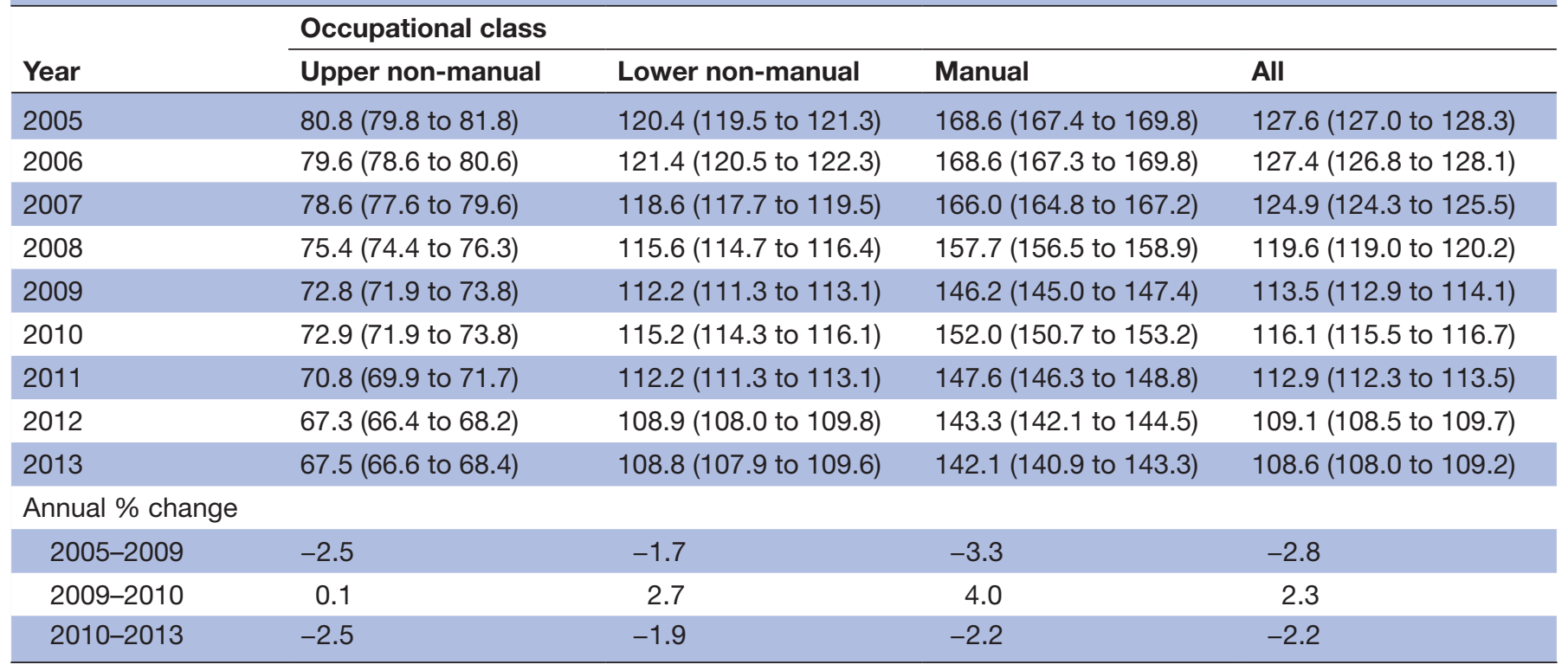

characteristics are presented in online supplementary table 1. Average distributions over the whole study period are presented also separately for those employed in different industrial sectors within different occupational classes in online supplementary table 2 .

\section{Sickness absence trends by occupational class}

Upper non-manual employees had the lowest and manual workers the highest overall level of sickness absence (table 2). Among the total study population, the age-adjusted and gender-adjusted proportion of employees with any sickness absence decreased from $127.6 \%$ in 2005 to $108.6 \%$ in 2013. Until 2009, the annual decrease was largest among manual workers. Between 2009 and 2010, sickness absence increased, but only among manual workers and lower non-manual employees. After 2010, the decrease in sickness absence continued. Overall, the decrease in sickness absence was smallest among lower non-manual employees.

The occupational class differences in sickness absence varied by disease group in terms of both the overall level and time trends (figure 1). In terms of the overall level, the differences were particularly large in musculoskeletal diseases (figure 1A) and negligible in neoplasms (figure 1G). In mental disorders (figure 1B), the level was highest among lower non-manual employees.

In terms of trends, the decrease in absences due to musculoskeletal diseases (figure 1A) was mainly restricted to manual workers, leading to decreasing class differences particularly until 2009. In mental disorders (figure $1 \mathrm{~B}$ ) and digestive diseases (figure $1 \mathrm{~F}$ ), the decrease in absences was slightly smaller among lower non-manual employees than among the other classes. In respiratory diseases (figure 1E), the overall decreasing trend was interrupted by an increase in absences between 2007 and 2011, most notably so among lower non-manual employees. In circulatory diseases (figure 1D), absences decreased over the study period with no clear differences between the classes. In neoplasms (figure 1C), the changes over time were relatively small.

Adjustment for other socioeconomic factors and employment patterns attenuated the occupational class differences in sickness absence levels, but it had little effect on the varying trends between the classes (figure 1 , model 2 compared with model 1).

\section{Sickness absence trends by industrial sectors within occupational classes}

We examined age-adjusted and gender-adjusted (online supplementary figure 1) as well as fully adjusted (figure 2) annual proportions of cause-specific sickness absence by industrial sectors within the three occupational classes. Although adjustment for socioeconomic factors and employment patterns attenuated the industrial sector differences in the overall absence levels, it had little influence on the varying trends (figure 2 compared with online supplementary figure 1). All further results are therefore based on the fully adjusted models.

Among upper (figures 2A,B and 3A,B) and lower (figures 2C,D and 3C,D) non-manual employees, the overall level of sickness absence due to both musculoskeletal diseases and mental disorders was highest in the health and social work sector. Among manual workers, the absence level in musculoskeletal diseases (figures $2 \mathrm{E}$ and $3 \mathrm{E}$ ) was highest in the manufacturing sector, whereas in mental disorders (figures $2 \mathrm{~F}$ and $3 \mathrm{~F}$ ) there was no consistent variation between the sectors.

Among lower non-manual employees (figure 2C) and manual workers (figure 2E), the decrease in absences due to musculoskeletal diseases was smaller in the trade sector than in the other sectors. As a result, the excess risk in the trade sector compared with the 

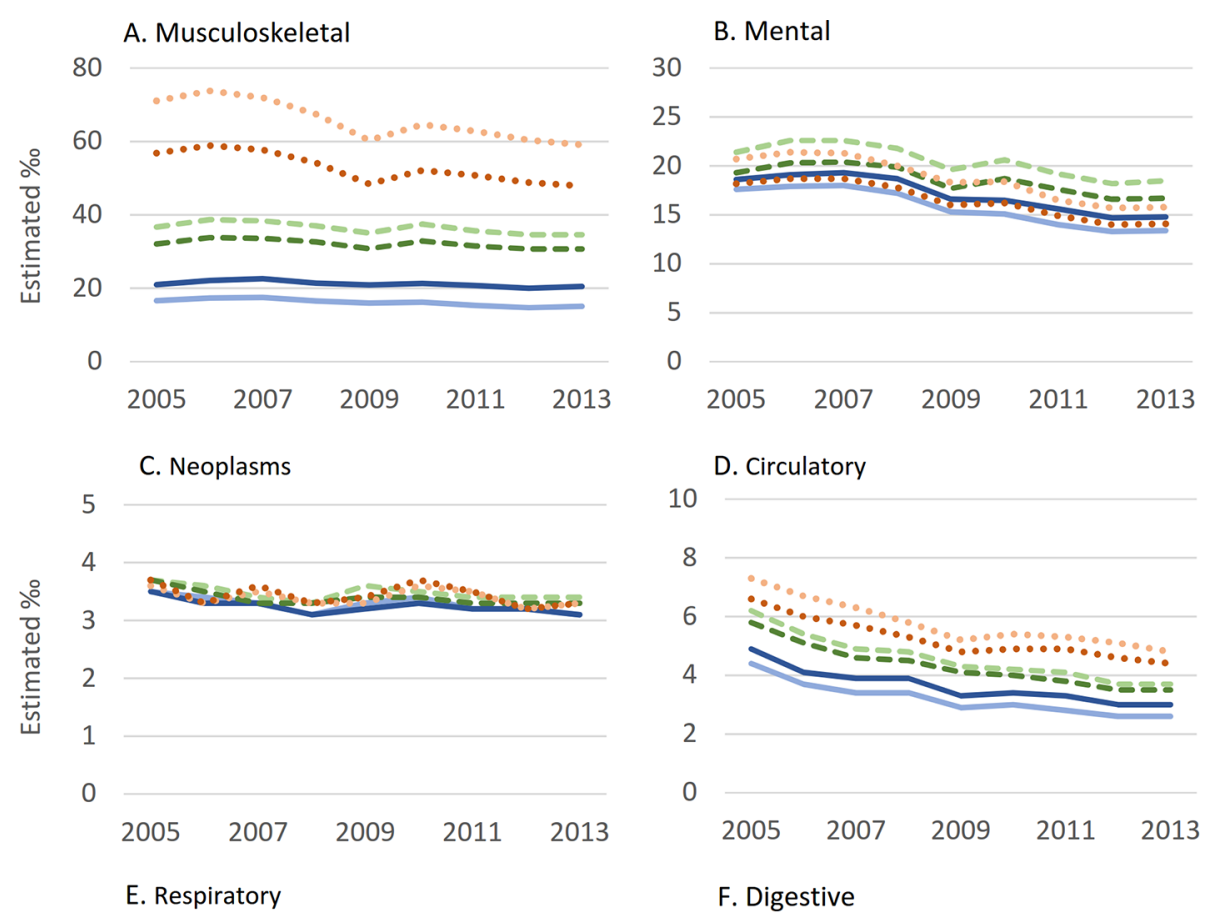

10
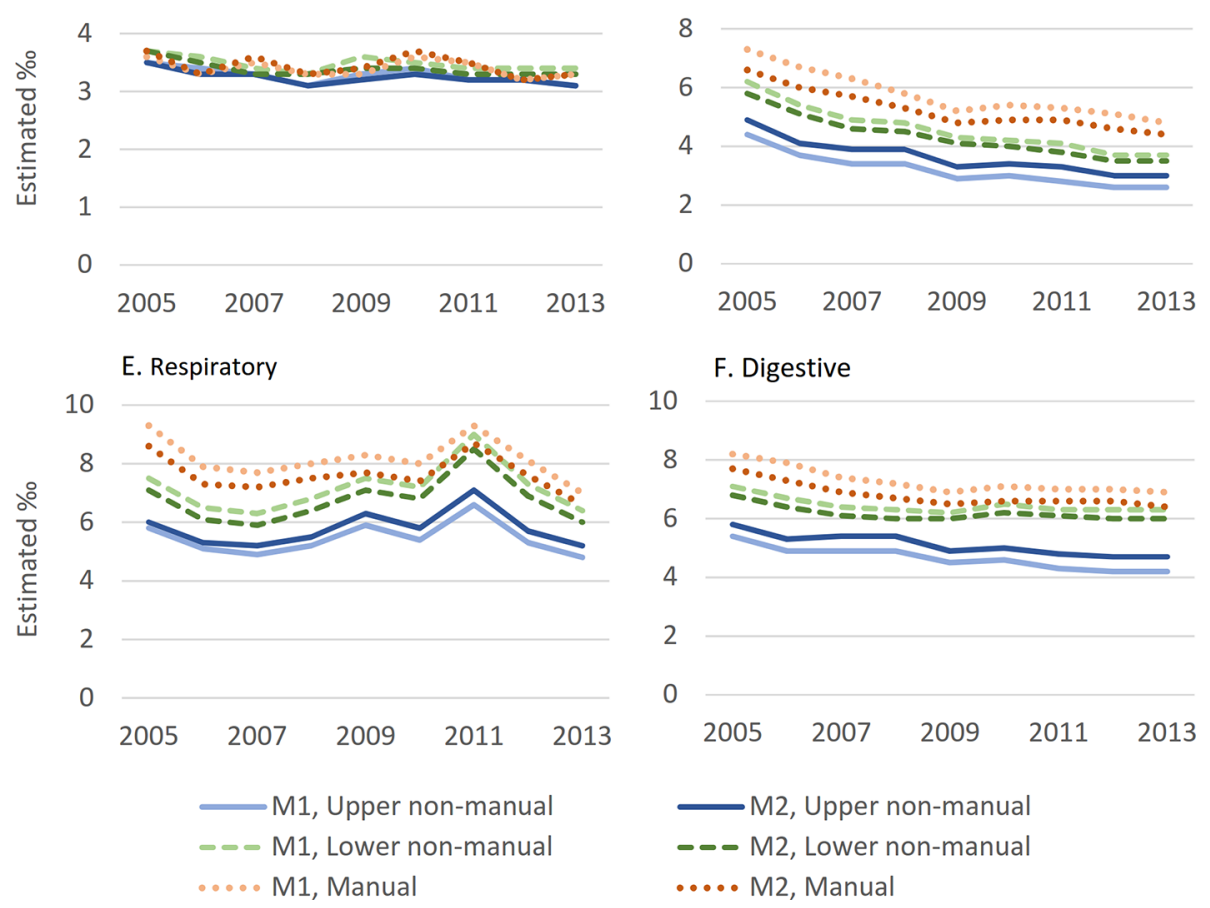

Figure 1 Estimated annual proportion of employees with a new onset of cause-specific (A-F) sickness absence (\%) by occupational class. The panels are presented in different scales; model 1 (M1): adjusted for age and gender; model 2 (M2): adjusted for age, gender, education, industrial sector, employment sector, income, time spent in employment and the number of employment episodes; $p$ values for the interaction between occupational class and year: (A) M1: 0.000, M2: 0.000, (B) M1: 0.000, M2: 0.000, (C) M1: 0.099, M2: 0.100, (D) M1: 0.035, M2: 0.041, (E) M1: 0.000, M2: 0.000, (F) M1: 0.021, M2: 0.165.

reference group of knowledge work increased over the study period (figure 3C,E). The temporary decrease in absences due to musculoskeletal diseases around year 2009 was particularly large among manual workers (figure 2E) in the manufacturing sector, which led to a temporary decrease in the excess risk found in this sector (figure 3E). Also in mental disorders, there were corresponding but smaller temporary decreases around year 2009 in the manufacturing sector among lower non-manual employees (figures 2D and 3D) and manual workers (figures $2 \mathrm{~F}$ and $3 \mathrm{~F}$ ). Furthermore, there was no decrease over the study period in absences due to mental disorders among upper non-manual employees (figure 2B) in the manufacturing sector. The absence level was originally lowest in this sector, but by the end of the study period, the reduced risk compared with the reference group of knowledge work disappeared (figure 3B). Otherwise, the differences in sickness absence between industrial sectors remained relatively stable over the study period.

\section{DISCUSSION}

We used large register-based datasets on the general population of Finnish wage earners in order to provide novel information on occupational class and industrial sector differences in cause-specific sickness absence trends. We accounted for the potential influence of changes in other socioeconomic factors and employment patterns on the varying trends. Although both occupational and sectoral differences in sickness absence have been previously examined, ${ }^{1-14}$ our study is, to our knowledge, the first one to examine differences in sickness absence between industrial sectors within particular occupational classes. 
A. Upper non-manual, Musculoskeletal

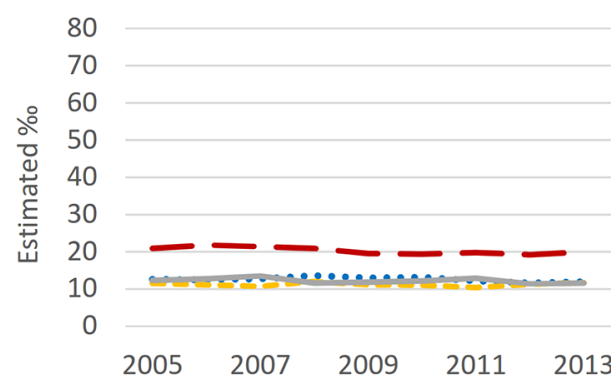

C. Lower non-manual, Musculoskeletal

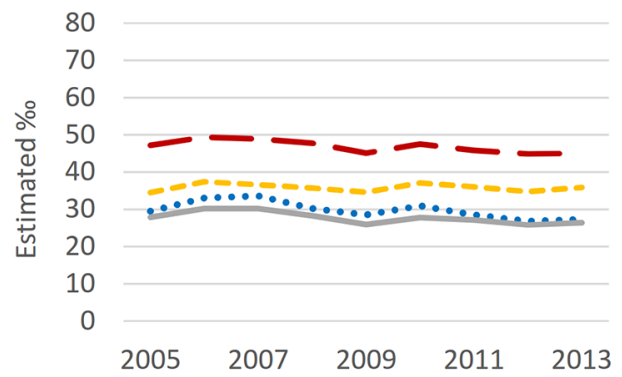

E. Manual, Musculoskeletal

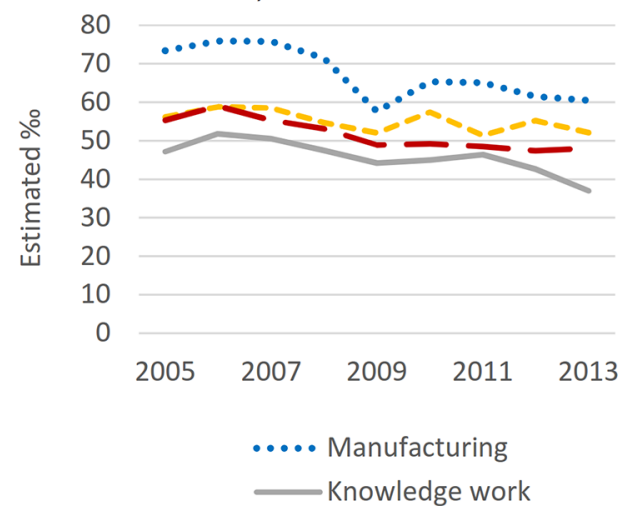

B. Upper non-manual, Mental

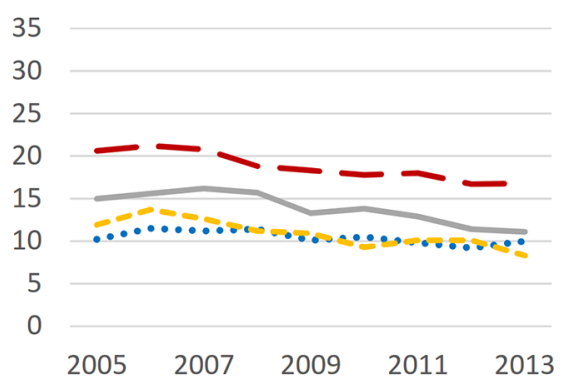

D. Lower non-manual, Mental

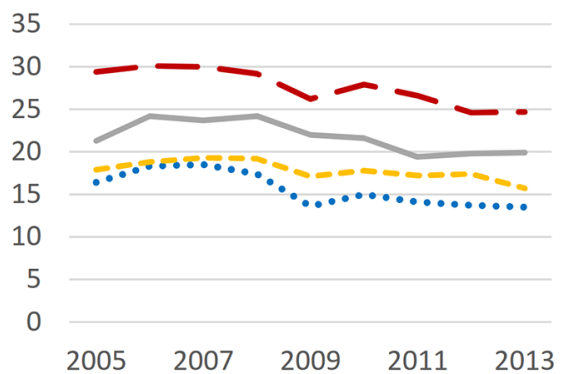

F. Manual, Mental

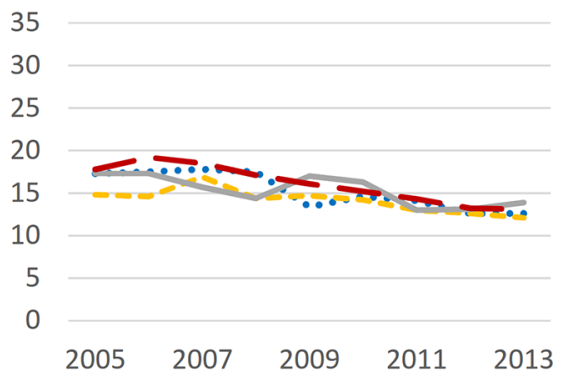

$-\infty$ Trade

- Health \& social work

Figure 2 Estimated annual proportion of employees with a new onset of sickness absence due to musculoskeletal diseases and mental disorders (\%) by industrial sector among (A-B) upper non-manual employees, (C-D) lower non-manual employees and (E-F) manual workers. The panels are presented in different scales; adjusted for age, gender, education, employment sector, income, time spent in employment and the number of employment episodes; $\mathrm{p}$ values for the interaction between industrial sector and year: (A) 0.550, (B) 0.053, (C) 0.014, (D) 0.001, (E) 0.000, (F) 0.000.

We found that the proportion of employees with sickness absence lasting more than 10 working days generally decreased between 2005 and 2013 in all of the examined occupational classes. All in all, the change was smallest among lower non-manual employees. Upper non-manual employees had the lowest and manual workers the highest overall level of sickness absence. The occupational class differences in the overall absence levels were particularly large in musculoskeletal diseases. In this disease group, the decrease in absences nevertheless restricted to manual workers, leading to a reduction in the class differences over time. In mental disorders, in contrast, the absence level was highest and the decrease over time smallest among lower non-manual employees. This led to increasing class differences over time. Also in respiratory and digestive diseases, the decreases over time were smallest among lower non-manual employees. In circulatory diseases, absences decreased in all occupational classes, whereas in neoplasms, the changes over time where altogether small.

Looking at the two largest disease groups, that is, musculoskeletal diseases and mental disorders, we found further variation in sickness absence between four large industrial sectors despite the fact that these were examined within particular occupational classes. Among non-manual employees, the overall absence levels were highest in the health and social work sector. Among manual workers, the level in musculoskeletal diseases was highest in the manufacturing sector, where a notable temporary decrease in absences nevertheless occurred during the peak of the economic recession in 2009. Among manual workers and lower non-manual employees, the decrease in absences due to musculoskeletal diseases was smallest in the trade sector.

The contribution of the recession of the late 2000s to changes in the occupational class differences in sickness 
A. Upper non-manual, Musculoskeletal

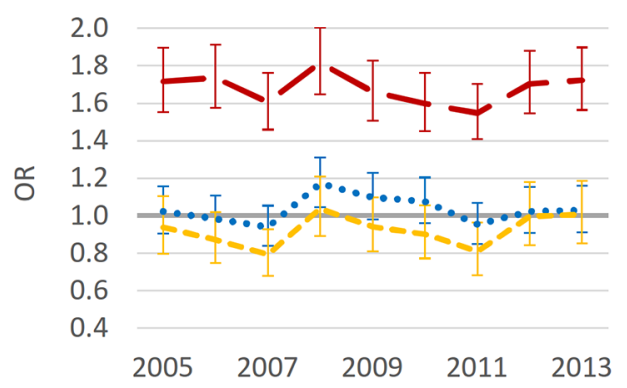

C. Lower non-manual, Musculoskeletal

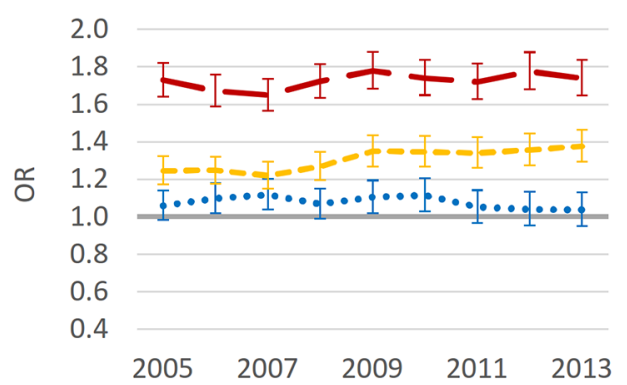

E. Manual, Musculoskeletal

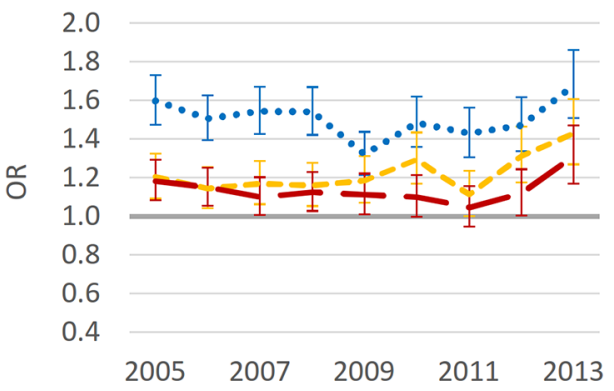

B. Upper non-manual, Mental

2.0

1.8
1.6

1.6

1.2

1.0

0.8

0.6

0.4

$2005 \quad 2007 \quad 2009 \quad 2011 \quad 2013$

D. Lower non-manual, Mental

2.0

1.8

1.6

1.4

1.2

1.0

0.8

0.6

0.4

$20052007 \quad 20092011 \quad 2013$

F. Manual, Mental

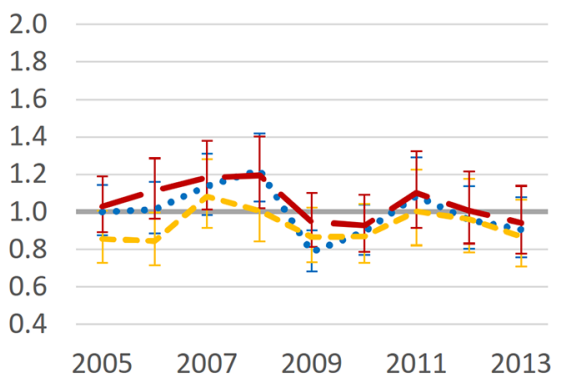

- Health \& social work

Figure 3 Annual risk (ORs and their 95\% Cls) of having a new onset of sickness absence due to musculoskeletal diseases and mental disorders by industrial sector (OR=1.00 for the knowledge work sector in each year) among (A-B) upper non-manual employees, (C-D) lower non-manual employees and (E-F) manual workers. Adjusted for age, gender, education, employment sector, income, time spent in employment and the number of employment episodes; $p$ values for the interaction between industrial sector and year: (A) 0.550, (B) 0.053, (C) 0.014, (D) 0.001, (E) 0.000, (F) 0.000.

absence has not been clear. A previous study on municipal employees in the 1990s indicated that occupational class differences in the number of new all-cause sickness absence spells lasting over 3 days were smaller in the recession years than in the following period of economic growth. ${ }^{3}$ Accordingly, we found that the class differences were smallest in 2009, that is, during the peak of the more recent economic recession. Moreover, we found that changes in the class differences around the time of the recession were largest in musculoskeletal diseases. We also found that the temporary sharp decline in absences in 2009 was most pronounced among manual workers employed in the manufacturing sector. This was the group in our data for which employment decreased most around the time of the recession. In addition to decreases in musculoskeletal morbidity and physically demanding work, it is thus likely that the recession itself was a driving factor behind the decline in sickness absence, especially among manual workers employed in the manufacturing sector. Employees who were strongly affected by labour market insecurity and the threat of unemployment may have been less willing to be absent from work despite their health problems. ${ }^{121-23}$ It is also possible that during the recession, affected groups of employees had stronger ill-health-related selection out of employment. ${ }^{24-26}$ The decline in sickness absence during the recession could thus have been attributable to excess employment exit among individuals with a higher likelihood of sickness absence. $^{27}$

Our finding on the smaller decrease among lower non-manual employees in sickness absence due to mental, respiratory and digestive diseases was not explained by changes in the distribution of factors that were measured in this study, including education, income and employment patterns. The smaller decrease in sickness absence among lower non-manual employees may therefore 
have been related to unobserved unfavourable changes in their work environment such as increased psychosocial demands during the period of economic downturn. It may also have been related to labour market changes that reduced sickness absence in the other two occupational classes. However, according to previous findings from Finland, trends in job quality appear to have been relatively similar between occupational classes over our study period. ${ }^{28}$ Other findings nevertheless indicated polarisation in the labour market of Finland and other Nordic countries between the mid-1990s and mid-2000s, which was interpreted as partly relating to technological advances in the period. The proportion of occupations at both the top and the bottom ends of the wage distribution increased: engineering professionals and other professionals at the top level and personal and protective services at the bottom level became more common. Accordingly, the proportion of occupations at the intermediate level of the wage distribution decreased mainly due to a reduction in office clerks, that is, routine non-manual employees. ${ }^{29}$ Corresponding changes may have occurred in our study period and affected the job distributions within the occupational classes. A further notable change in the Finnish labour market is that the proportion of employees performing distant work increased from $10 \%$ in 2003 to $20 \%$ in $2013 .{ }^{30}$ This may have contributed to the decrease in sickness absence among particular groups of employees. It is likely that upper non-manual employees are more able to perform distant work while being ill than lower non-manual employees or manual workers.

The generally higher absence levels that we found in the health and social work sector are in accordance with previous studies. ${ }^{12}{ }^{13}$ Findings from Norway indicated that the higher risk of sickness absence among those employed in health and social occupations was largely explained by their unfavourable psychosocial and physical working conditions. ${ }^{13}$ A Finnish study also showed that employees in the combined sector of education, health and social work had poorer health in terms of a higher risk of hospitalisation compared with those in other sectors. This applied to various disease groups, including musculoskeletal diseases and mental disorders. Furthermore, the risk of hospitalisation at least due to musculoskeletal diseases was higher in the manufacturing sector than in the trade and knowledge work-related sectors. ${ }^{31}$ The present study adds to the literature by indicating that the higher level of sickness absence in the health and social work sector compared with other sectors was generally found in both musculoskeletal diseases and mental disorders. However, our novel findings further indicated that this sector difference was only found among non-manual employees. Among manual workers, the absence level in musculoskeletal diseases was highest in the manufacturing sector.

Our study also indicated that the differences in sickness absence between industrial sectors within the occupational classes were relatively stable since the mid-2000s. Exceptions included the above discussed temporary fluctuations around 2009 and the smaller decrease in absences due to musculoskeletal diseases in the trade sector compared with other ones within the lower classes. The more unfavourable trends of the trade sector were not explained by changes in the distribution of any of the measured socioeconomic factors and employment patterns. More research is needed to determine whether, for example, changes in working conditions or types of jobs within the trade sector contributed to the trends.

Overall, our findings indicated that the occupational class and industrial sector differences in sickness absence trends largely depended on the disease causing work disability. In musculoskeletal diseases, the changes over time varied most. Musculoskeletal diseases may be considered as work related and their diagnoses are often symptom based. Changes in the work or economic conditions may have affected how particular groups of employees cope with their symptoms and behave while being ill. In other causes such as circulatory diseases, the decrease in absences was more consistent across the classes, which may have been related to equality in terms of decreased morbidity and improved treatment.

The strengths of this study included nationally representative samples of the Finnish population and register-based datasets that did not have the problem of missing information due to non-response. The rich data comprised longitudinal information on employment and sociodemographic factors as well as on sickness absence and its diagnostic cause. Furthermore, the very large samples allowed us to examine cause-specific sickness absence between industrial sectors within different occupational classes, thereby capturing occupational groups with relatively similar types of jobs. Our findings may be generalisable to countries in which the manufacturing sector in particular was affected by the recession of the late 2000s and in which also the sickness benefit system is relatively generous.

There were nevertheless also certain limitations. Our outcome measure was based on national data on compensated sickness absence spells that begin after a period of 10 working days. Sickness absence spells that did not exceed 10 working days were therefore not covered. Moreover, our outcome measure was based on new onset of sickness absence. The predictors of sickness absence might be different when examining, for example, the occurrence of short-term spells, the number of spells of different lengths or the total number of absence days. ${ }^{32-36}$

Although our results indicated that other socioeconomic factors and employment patterns partly explained the occupational class and industrial sector differences in the overall level of cause-specific sickness absence, they did not appear to explain the varying trends. Factors that were not measured in this study, such as changes in health, lifestyle, work exposures and labour market conditions, were therefore likely to have contributed to the differences in the trends. Sickness absence trends may have been affected also by changes in national 
sickness insurance legislation aiming at enhancing work participation. ${ }^{37-39}$

It should be noted that the recession might have led to a larger health inequality between the employed and non-employed populations than between the different socioeconomic groups among the employed. Focusing on sickness absence among an employed population may therefore not have revealed some of the potential effects of the recent economic recession on health and health inequalities. ${ }^{40-44}$

\section{CONCLUSIONS}

The proportion of wage earners with sickness absence lasting more than 10 working days decreased in Finland between 2005 and 2013 in all occupational classes. Overall, the change was smallest among lower non-manual employees. Occupational class differences in sickness absence trends nevertheless varied by disease group. There were notable and relatively stable differences in sickness absence between industrial sectors even when these were examined within particular occupational classes. Moreover, the association between industrial sector and sickness absence varied across the occupational classes. At the time of the economic recession of the late 2000s, there was a temporary decrease in sickness absence due to musculoskeletal diseases specifically among manual workers employed in the manufacturing sector, that is, in a segment of wage earners who are known to have been hit hard by the recession. However, differences in the trends among occupational classes and industrial sectors were not explained by the measured structural changes in other socioeconomic factors or employment patterns. The complex interplay between occupational class and industrial sector should be taken into account when tackling problems of work disability.

Contributors EV-J obtained the data. SS and EV-J conceived the study. TL, SS, EV-J and KH-P designed the study. SS and TL prepared the data for analyses. TL conducted the statistical analyses. TL, SS, EV-J and KH-P contributed to interpretation of the results. TL wrote the first drafts of the article. TL, SS, EV-J and $\mathrm{KH}-\mathrm{P}$ discussed and revised the drafts and prepared the final manuscript.

Funding This work was supported by the Academy of Finland (project numbers 267589 and 303534 to Viikari-Juntura), NordForsk (project number 76659 to Solovieva) and the Finnish Work Environment Fund (project number 115105 to Solovieva).

\section{Competing interests None declared.}

Patient consent Detail has been removed from this case description/these case descriptions to ensure anonymity. The editors and reviewers have seen the detailed information available and are satisfied that the information backs up the case the authors are making.

Ethics approval The researchers used fully anonymous register data. Research using such data does not need to undergo review by an ethics committee according to Finnish legislation. Statistics Finland linked its data to those of the Social Insurance Institution of Finland and the Finnish Centre for Pensions, after which the data were anonymised and stored by Statistics Finland. The researchers analysed the anonymous data using a remote access system. The output extracted from the system was approved by Statistics Finland to ensure compliance with data protection regulations. The data can only be accessed by the individual researchers who have obtained permission from each of the administrative sources providing the data.
Provenance and peer review Not commissioned; externally peer reviewed.

Data sharing statement Due to data protection regulations of the administrative sources providing the register data, the authors do not have the permission to share the data. Permissions to use the register data can be applied from the Social Insurance Institution of Finland (http://www.kela.fi/web/en/research-data-requests), the Finnish Centre for Pensions (http://www.etk.fi/en/statistics-2/statistics/ producer-of-statistics/) and Statistics Finland (http://www.stat.fi/meta/tietosuoja/ kayttolupa_en.html).

Open Access This is an Open Access article distributed in accordance with the Creative Commons Attribution Non Commercial (CC BY-NC 4.0) license, which permits others to distribute, remix, adapt, build upon this work non-commercially, and license their derivative works on different terms, provided the original work is properly cited and the use is non-commercial. See: http://creativecommons.org/ licenses/by-nc/4.0/

(c) Article author(s) (or their employer(s) unless otherwise stated in the text of the article) 2018. All rights reserved. No commercial use is permitted unless otherwise expressly granted.

\section{REFERENCES}

1. Allebeck P, Mastekaasa A. Swedish council on technology assessment in health care (SBU). Chapter 5. Risk factors for sick leave - general studies. Scand J Public Health Suppl 2004;63:49-108.

2. Melchior M, Krieger N, Kawachi I, et al. Work factors and occupational class disparities in sickness absence: findings from the GAZEL cohort study. Am J Public Health 2005;95:1206-12.

3. Piha K, Martikainen P, Rahkonen O, et al. Trends in socioeconomic differences in sickness absence among Finnish municipal employees 1990-99. Scand J Public Health 2007;35:348-55.

4. Christensen KB, Labriola M, Lund T, et al. Explaining the social gradient in long-term sickness absence: a prospective study of Danish employees. J Epidemiol Community Health 2008;62:181-3.

5. Hansen H-T, Ingebrigtsen T. Social class and sickness absence in Norway. Acta Sociol 2008;51:309-27.

6. Piha K, Laaksonen M, Martikainen P, et al. Interrelationships between education, occupational class, income and sickness absence. Eur J Public Health 2010;20:276-80.

7. d'Errico A, Costa G. Socio-demographic and work-related risk factors for medium- and long-term sickness absence among Italian workers. Eur J Public Health 2012;22:683-8.

8. Löve J, Hensing G, Holmgren $\mathrm{K}$, et al. Explaining the social gradient in sickness absence: a study of a general working population in Sweden. BMC Public Health 2013;13:545.

9. Pekkala J, Blomgren J, Pietiläinen $O$, et al. Occupational class differences in long sickness absence: a register-based study of 2.1 million Finnish women and men in 1996-2013. BMJ Open 2017;7:e014325.

10. Pekkala J, Blomgren J, Pietiläinen O, et al. Occupational class differences in diagnostic-specific sickness absence: a register-based study in the Finnish population, 2005-2014. BMC Public Health 2017;17:670.

11. Sumanen $\mathrm{H}$, Lahelma $\mathrm{E}$, Pietiläinen $\mathrm{O}$, et al. The magnitude of occupational class differences in sickness absence: 15-year trends among young and middle-aged municipal employees. Int J Environ Res Public Health 2017;14:625.

12. Lund $T$, Labriola M, Villadsen $E$. Who is at risk for long-term sickness absence? A prospective cohort study of Danish employees. Work 2007;28:225-30.

13. Aagestad C, Tyssen R, Sterud T. Do work-related factors contribute to differences in doctor-certified sick leave? A prospective study comparing women in health and social occupations with women in the general working population. BMC Public Health 2016;16:235.

14. Knutsson A, Goine H. Occupation and unemployment rates as predictors of long term sickness absence in two Swedish counties. Soc Sci Med 1998;47:25-31.

15. Bettio F, Corsi M, D'lppoliti C, et al. The impact of the economic crisis on the situation of women and men and on gender equality policies. Synthesis report. Luxembourg: Publications Office of the European Union, 2013.

16. Statistics Finland. StatFin online service. 2017 http://www.stat.fi/tup/ statfin/index_en.html (accessed 13 Dec 2017).

17. European Commission. Employment and social developments in Europe. Luxembourg: Publications Office of the European Union, 2017. 
18. Leinonen T, Viikari-Juntura E, Husgafvel-Pursiainen $\mathrm{K}$, et al. Labour market segregation and gender differences in sickness absence: trends in 2005-2013 in Finland. Ann Work Expo Health 2017. 10.1093/annweh/wxx107. [Epub ahead of print 29 Dec 2017].

19. The Social Insurance Institution of Finland. Sickness allowance. 2017 http://www.kela.fi/web/en/sickness-allowance (accessed 8 Dec 2017)

20. Statistics Finland. Classifications. 2017 https://www.stat.fi/meta/ luokitukset/index_en.html (accessed 2 Jan 2018).

21. Askildsen JE, Bratberg E, Nilsen OA. Unemployment, labor force composition and sickness absence: a panel data study. Health Econ 2005;14:1087-101.

22. Virtanen M, Kivimäki M, Elovainio M, et al. Local economy and sickness absence: prospective cohort study. J Epidemiol Community Health 2005:59:973-8.

23. Pfeifer $\mathrm{C}$. Cyclical absenteeism among private sector, public sector and self-employed workers. Health Econ 2013;22:366-70.

24. Evans-Lacko S, Knapp M, McCrone P, et al. The mental health consequences of the recession: economic hardship and employment of people with mental health problems in 27 European countries. PLoS One 2013;8:e69792.

25. Heggebø K. Unemployment in Scandinavia during an economic crisis: cross-national differences in health selection. Soc Sci Med 2015;130:115-24.

26. Heggebø K, Dahl E. Unemployment and health selection in diverging economic conditions: Compositional changes? Evidence from 28 European countries. Int J Equity Health 2015;14:121

27. Hesselius P. Does sickness absence increase the risk of unemployment? J Socio Econ 2007;36:288-310.

28. Mustosmäki A, Oinas T, Anttila T. Abating inequalities? Job quality at the intersection of class and gender in Finland 1977-2013. Acta Sociol 2017;60:228-45.

29. Asplund R, Barth E, Lundborg P, et al. Polarization of the Nordic labour markets. Finnish Economic Papers 2011;24:87-100.

30. Sutela H, Lehto A-M. Työolojen muutokset 1977-2013 [Changes in working conditions 1977-2013]. Helsinki: Tilastokeskus, 2014.

31. Kokkinen L, Kouvonen A, Koskinen A, et al. Differences in hospitalizations between employment industries, Finland 1976 to 2010. Ann Epidemiol 2014;24:598-605.

32. Melchior M, Niedhammer I, Berkman LF, et al. Do psychosocial work factors and social relations exert independent effects on sickness absence? A six year prospective study of the GAZEL cohort. $J$ Epidemiol Community Health 2003;57:285-93.
33. Alavinia SM, van den Berg TI, van Duivenbooden C, et al. Impact of work-related factors, lifestyle, and work ability on sickness absence among Dutch construction workers. Scand J Work Environ Health 2009;35:325-33

34. Kristensen TR, Jensen SM, Kreiner S, et al. Socioeconomic status and duration and pattern of sickness absence. A 1-year follow-up study of 2331 hospital employees. BMC Public Health 2010;10:643

35. Laaksonen M, Pitkäniemi J, Rahkonen O, et al. Work arrangements, physical working conditions, and psychosocial working conditions as risk factors for sickness absence: Bayesian analysis of prospective data. Ann Epidemiol 2010;20:332-8.

36. Magnavita N, Garbarino S. Is absence related to work stress? A repeated cross-sectional study on a special police force. Am J Ind Med 2013;56:765-75.

37. Kausto J, Viikari-Juntura E, Virta LJ, et al. Effectiveness of new legislation on partial sickness benefit on work participation: a quasiexperiment in Finland. BMJ Open 2014;4:e006685.

38. Halonen JI, Solovieva S, Pentti J, et al. Effectiveness of legislative changes obligating notification of prolonged sickness absence and assessment of remaining work ability on return to work and work participation: a natural experiment in Finland. Occup Environ Med 2016;73:42-50.

39. Viikari-Juntura E, Virta LJ, Kausto J, et al. Legislative change enabling use of early part-time sick leave enhanced return to work and work participation in Finland. Scand J Work Environ Health 2017;43:447-56.

40. Bacigalupe A, Esnaola S, Martín U. The impact of the Great Recession on mental health and its inequalities: the case of a Southern European region, 1997-2013. Int J Equity Health 2016;15:17

41. Bruggink JW, de Goeij MC, Otten F, et al. Changes between precrisis and crisis period in socioeconomic inequalities in health and stimulant use in Netherlands. Eur J Public Health 2016;26:772-7.

42. Frasquilho D, Matos MG, Salonna F, et al. Mental health outcomes in times of economic recession: a systematic literature review. BMC Public Health 2016;16:115.

43. Parmar D, Stavropoulou C, loannidis JP. Health outcomes during the 2008 financial crisis in Europe: systematic literature review. BMJ 2016;354:i4588.

44. Nelson K, Tøge AG. Health trends in the wake of the financial crisisincreasing inequalities? Scand J Public Health 2017;45:22-9. 